\title{
The National Nutrition Conference
}

$\mathrm{T}$ HE modern State accepts without serious question the duty of applying, without stint, all the resources of science and finance to the effective defence of its citizens from enemy attack. It would appear at least equally important that the democratic State should utilize all the help of modern science to make its citizens worth protecting.

The cost in money of providing proper and adequate food for every citizen in Great Britain who at present is unable to provide it for himself is at the worst only a fraction of the cost of defensive armaments, whilst the cost in disease, in social and industrial or even military inefficiency and in sheer human distress of allowing malnourishment to continue is one that no civilized people can afford.

An adequate scientific basis has existed for several years for a positive national nutrition policy linking health and agriculture; there has been wide discussion of the bases of such a policy, and an increasing demand from several quarters that it be put into practice. This policy would on one hand provide the benefits of a sufficient supply of total nutrients, and in particular of protective foods-milk and dairy produce, fresh fruit and vegetables, eggs, fish, and, to a lesser extent, fresh meat, most of which are produced at home or in the Dominions-to citizens of all ages; and on the other hand it would assist the home farmer by giving him a much larger and guaranteed market for that type of human food which the climate and soil of Great Britain are particularly suited to provide.

All interested in the development of a healthy, physically fit citizen must therefore have welcomed the decision of the British Medical Association to call a national conference to deal with the wider aspects of nutrition.

The conference was duly held during April 2729 at British Medical Association House. In view of quality of the discussions and the character of the participants-there were many senior representatives of medicine, physiology and nutritional science, agriculture at home and abroad, industry, social services, and education presentits pronouncements can only be ignored by a Whitehall completely insensitive to informed public opinion. With our present Government, these discussions can scarcely fail to encourage those who frame our policy to act, and to act quickly. The gap between the extent of our nutritional knowledge and the social utilization of such knowledge on a national scale has been widening steadily, and further delay can only mean, in terms of readily understood coinage, inferior recruits, persistent industrial inefficiency, continued high expenditure on hospitals and sanatoria, and more subsidies of the wrong kind to farmers, and, in terms of a different coinage, an unconscionable waste of human life, happiness and potentialities.

The conference covered a wide field. The inaugural address was delivered by Sir Arthur Salter, M.P., who summarized the general findings of recent nutritional surveys in Great Britain and recalled the inevitable conclusions drawn as to the inverse relationship, on the whole, between income on one hand, and disease and death-rates on the other. $\mathrm{He}$ pointed out the great part played by milk in the prevention of malnutrition, the severe economic penalty now attached to large, or even moderate families, and the necessity that the cost of the major items in the cost of living figure should be kept to an absolute minimum. One of the policies he advised is a standard guaranteed price to home producers of the more important foodstuffs. He criticized severely some of the recent measures adopted by the State to help farmers as ill-conceived and wasteful, and in particular the weaknesses inherent in the Agricultural Marketing Acts. By this legislation, for example, the consumer price of milk is controlled by the statutory power of the Milk Marketing Board, a body composed solely of producers, which must inevitably consider milk primarily as the channel of an important part of the farmer's income, and only secondarily as the most essential of foods. The whole system of control should be reformed so as to make the public interest prevail.

Sir Arthur gave an account of the present position of Great Britain as regards food storage requirements, and urged the need for provision of food reserves on a much more adequate scale than anything that has yet been done. One per cent of our annual defence expenditure would provide the total sum required to handle the necessary quantities.

Following the inaugural address came a discussion on the physiological aspects (miscalled in the programme the 'medical' aspects) of nutrition. Prof. E. P. Cathcart pointed out that proper nutrition depends not only on an adequate and balanced food intake, but also on exercise, sleep, housing and working conditions, and adequate relaxation of body and mind. He made a cautious 
survey of some of the requirements of an adequate diet, emphasized the need for education on how best to spend a relatively low income and how to make the best use of available foodstuffs. Dietary habits, despite man's natural conservatism as regards food, are changing for the better. It is most desirable to study the means by which this slow change in dietary habits could be accelerated. Dr. G. P. Crowden mentioned, inter alia, one of the ways in which this is being done, namely, by wide circulation of small, inexpensive household guides on sound dietetic lines, containing shopping lists, menus and recipes.

Major-General Sir Robert McCarrison, in a cogent contribution, emphasized that there is now no controversy about the main principles of nutrition. Food, as fresh and natural as possible, produced from unimpoverished soil, is the main factor for health. He regards malnutrition as essentially a functional disturbance, and only in its later stages does malnutrition lead to gross bodily changes. His plea for more precise methods of assessing malnutrition, especially in the young, was repeated time and again throughout the conference. Another factor requiring further research and elucidation is 'freshness' in food. What exactly does freshness mean, and how important is it, nutritionally? This was mentioned by several speakers. Later speakers also stressed the real need for keeping clearly distinct the minimal diet, on which health might be barely maintained, and the optimal diet which, without excess, provides a factor of safety.

The second session, on the "Means of Stimulating Production (a) Home Agriculture" was under the chairmanship of Sir John Russell. The thesis of Lord Astor's paper, which immediately followed the chairman's pertinent remarks as to possible ways of reorganizing agriculture, was that the abolition of malnutrition should be the next major social reform. He, in common with other speakers, expressed deep dissatisfaction with recent agricultural-cum-nutritional policy. It is high time that a home agriculture should be developed which is more suited to our times and needs-among which adequate nutrition of the whole population is the foremost-and which avails itself more freely of recent scientific and mechanical progress. Although home agriculture is still very much alive, the gross output of British farming being greater than it has ever been, he considers that, with the further spread of progressive methods of production, the protective foods could be provided for all consumers at cheaper rates than those now in force. Properly planned distribution, from which redundant services have been eliminated, can still further cheapen the consumer cost of milk, for example. These benefits should not be withheld any longer by marketing boards, whose present freedom from Parliamentary control should be withdrawn. $\mathrm{He}$ enlarged on the changes which might easily be brought about in milk production and would benefit producers and consumers alike, and regretted the hasty withdrawal last December of the Milk Industry Bill before it received proper consideration by Parliament. Public money is being spent on agriculture now in a wasteful way which helps only a few farmers. This money should be available to finance a properly conceived, national nutritional-cum-agricultural policy, which would bring health and welfare to millions, not least to the farmers themselves. Dr. Keith Murray, in a thoughtful paper, also gave reasons for believing that some form of subsidy from the Exchequer would be required, at least until such time as increased productive efficiency, a factor normally of slow operation, should have caught up.

Mr. Anthony Hurd agreed that farmers could make a much bigger contribution than they are making at present towards the better feeding of the human community, and also stressed the need for wider education in food values. Both he and Mr. Cleveland Fyfe regard it as essential to consider also the balance of farming and the need for the preservation of the fertility of the soil so that the generations of farmers who come after can continue to play their part without hindrance in the future feeding of the nation. Prof. W. C. Miller emphasized that the health and adequate nutrition of farm stock are prerequisites to the production of satisfactory dairy produce, poultry and eggs, and that any increasing demand for home-produced protective foods could not be met without a sound foundation, on the farm, of knowledge and practice of disease prevention. Proper housing, satisfactory methods of rearing, adequate exercise, as well as feeding, are as necessary to the farm animal as to the citizen, if health is to be maintained.

The direct interest of the Dominions and the role of the Dominion producer in Great Britain's nutritional policy were ably dealt with by Mr. F. L. McDougall (Australia) and by other Dominion representatives. A nutrition policy for the whole Empire is needed. Malnutrition exists in acute forms in various parts of the Empire, and, in fact, in the world at large. An effective endeavour to meet it would solve not only many of the problems of Dominion food producers, but probably also some of the international problems which underlie the present tension. Recent international agreements, far from remedying the acknowledged under-nourishment of half the world, have been agreements to restrict food production, to which Dominion Governments have been hesitant and unwilling partners. 
Mr. G. V. Jacks regards the high food output of some of the Dominions as the result of ruthless over-exploitation of stored soil fertility which will have to be paid for in the near future by diminished productivity due to soil exhaustion and soil erosion. In Great Britain and some of the older countries soil conservation, including manuring, draining, proper crop rotation, etc., has been carried out for centuries as a matter of course. The costs of this good farming represent the major part of the difference in costs of production between home produce and similar produce from the Dominions. Prof. S. M. Wadham would not accept this view as applying to Australia, where farmers over the really productive areas are fully alive to the danger of soil exhaustion and have already dealt with it.

There was nearly complete unanimity that lack of purchasing power among the lower income classes of the population is at present the main factor in faulty nutrition. Mr. L. S. Amery, M.P., in introducing the discussion on family allowances, pointed out that a wage system which takes no account of family needs and responsibilities is to-day inflicting grave hardships on millions of malnourished children. He made a convincing case, both on the grounds of simple social desirability and of the future industrial and defence needs of the country, for additional purchasing power for families in which there are growing children. Parents are now finding their own solution to the problem by refusing to have children, and as a consequence we are heading for national catastrophe at a speed measurable by the decline in the birth-rate. Family allowances should effect an appreciable saving on the $£ 300$ millions annually which the nation pays for ill-health, not to speak of the new wealth they would add through the positive increase of national efficiency. Mr. Amery's views were supported by Mr. Laurence Cadbury and Sir Kenneth Lee, who emphasized that no time should be lost in getting a national scheme into working order. Where private industrial schemes of family allowances are already in being, increased expenditure on food, that is, improved nutrition of the family, has been shown to be the major result. Extensions of the facilities for provision of free milk and meals direct to school children and to expectant and nursing mothers were advocated by Dr. Stella Churchill, not as a substitute for family allowances but as an efficient supplement to them. She emphasized that money spent on school meals and milk meant less spent on hospital beds, sanatoria, and unemployment in later life due to ill-health resulting from early malnutrition.

The final session of the conference, presided over by Sir Cyril Norwood, linked up the scheme for improved nutrition with education both in the schools and amongst adults. Mr. Lester Smith stated that the colleges at which housecraft teachers are trained are very much alive to their opportunity of improving national nutrition by training their students in what to eat, as well as how to cook it. He made the useful suggestion that school journeys ought to embrace visits to farms, market gardens and orchards, as well as to industrial and manufacturing concerns. The greater use of the radio for the education of the public in matters of health and nutrition was recommended by Prof. V. H. Mottram, and the part played by the women's institutes, whose membership is largely made up of those actually responsible for the purchase and cooking of the family food, was emphasized by Mrs. Henry Haldane. This discussion made it clear that one of the main requirements in our educational system, having in view the objective of an improved national nutritional status, is a greatly increased emphasis on the elements of science and their bearing on health, throughout school life. Through this educational channel every future consumer, housewife, farmer, administrator and statesman has to pass.

The text of the resolution passed at the end of the Conference may be given in full, as it marks a clear but conservative appeal which ought soon to be reflected in Government policy.

"This conference called by the British Medical Association and composed of representatives of Medicine, Agriculture at home and overseas, Industry and Education, is deeply impressed with the importance of nutrition to the national welfare. It urges upon the Government the formulation of a long-term food policy in which the requirements of Health, Agriculture and Industry shall be considered in mutual relation. It is convinced that measures to secure the more ready availability to all sections of the community of foodstuffs which are held to be desirable on nutritional grounds should be accompanied by an educational campaign to encourage their increased consumption."

It is reasonable to expect, in a democracy, that Government policy, particularly when dealing with home needs, will be largely under informed democratic control. If, with proper knowledge of the circumstances, public opinion asks for, and is ready to pay for, improved social conditions, then if democracy means anything at all an honest and pertinacious attempt must be made by executive authority to plan and provide the necessary services. The present international tension, far from excusing any delay in making such provision for an adequate long-term food policy, sharpens the need for it. 